\title{
Effects of Oil Tea on Obesity and Dyslipidemia: A Cross-Sectional Study in China
}

\author{
Jiansheng Cai (D) $1,2, *$ \\ Shuzhen Liu',* \\ You $\mathrm{Li}^{3, *}$ \\ Qiumei Liu' \\ Min $X u^{\prime}$ \\ Chunbao $\mathrm{Mo}^{3}$ \\ Tingyu $\mathrm{Mai}^{3}$ \\ Xia $X u^{\prime}$ \\ Xu Tang' \\ Quanhui Chen' \\ Chuntao Nong' \\ Huaxiang $\mathrm{Lu}^{1,3}$ \\ Haoyu $\mathrm{He}^{1,4}$ \\ Jiexia Tang 5 \\ Junling Zhang \\ Chunmei Wei' \\ Dechan $\operatorname{Tan}^{3}$ \\ Jian Qin' \\ Zhiyong Zhang ${ }^{1,3}$
}

'Department of Environmental and Occupational Health, School of Public Health, Guangxi Medical University, Nanning, 53002I, Guangxi Province, People's Republic of China; ${ }^{2}$ Guangxi Key Laboratory of Tumor Immunology and Microenvironmental Regulation, Guilin Medical University, Guilin, People's Republic of China;

${ }^{3}$ Department of Environmental Health and

Occupational Medicine, School of Public Health, Guilin Medical University, Guilin, People's

Republic of China; ${ }^{4}$ Quality Management

Department, the Affiliated Hospital of

Stomatology, Guangxi Medical University,

Nanning, People's Republic of China; ${ }^{5}$ Guangxi

Center for Disease Prevention and Control,

Nanning, People's Republic of China

*These authors contributed equally to this work

Correspondence: Jian Qin; Zhiyong Zhang Department of Environmental and Occupational Health, School of Public Health, Guangxi Medical University, Shuangyong Road No. 22, Nanning, 53002I, Guangxi Province, People's Republic of China

Tel +86-77l-5358124

Fax +86-77I-5358I24

Email qinjian@gxmu.edu.cn; rpazz@।63.com
Background: Animal experiments have found that oil tea reduces body weight and improves blood lipid levels. However, the effect of oil tea on human health has not been confirmed yet. This study aims to explore the relationship between oil tea consumption and obesity and dyslipidemia.

Methods: In a cross-sectional population study in Guangxi, China, a semi-quantitative questionnaire was used to investigate the oil tea consumed and food consumption frequency in adults aged 30 years and over. Anthropometric variables and serum biochemical indicators were measured. A total of 2001 adults were divided into five groups based on their non-consumption status and quartile of consumption (groups non-drink oil tea, Q1-Q4).

Results: The risk of abdominal obesity tended to decrease significantly with increasing consumption of oil tea ( $\mathrm{P}$ for trend $<0.05)$ in the overall participants $(\mathrm{Q} 3$ group, $\mathrm{OR}=$ $0.545,95 \% \mathrm{CI}=0.336-0.884 ; \mathrm{Q} 4$ group, $\mathrm{OR}=0.520,95 \% \mathrm{CI}=0.311-0.871)$ and in women $(\mathrm{Q} 2$ group, $\mathrm{OR}=0.502,95 \% \mathrm{CI}=0.274-0.920$; $\mathrm{Q} 3$ group, $\mathrm{OR}=0.397,95 \%$ $\mathrm{CI}=0.213-0.740 ; \mathrm{Q} 4$ group, $\mathrm{OR}=0.421,95 \% \mathrm{CI}=0.228-0.780)$. Oil tea consumption Q1, Q2, Q3 and Q4 group significantly reduced the risk of abnormal HDL-cholesterol $(P<0.05)$. Oil tea consumption $\mathrm{Q} 2$ group significantly increased the risk of abnormal LDL-cholesterol $(\mathrm{OR}=2.600,95 \% \mathrm{CI}=1.033-6.546)$ in women. Oil tea consumption $\mathrm{Q} 1(\mathrm{OR}=0.081,95 \% \mathrm{CI}=0.008-0.864)$ and $\mathrm{Q} 3(\mathrm{OR}=0.057,95 \% \mathrm{CI}=0.004-0.913)$ groups significantly reduced the risk of abnormal HDL-cholesterol in women.

Conclusion: Oil tea consumption may be associated with a low risk of abdominal obesity. High-dose oil tea consumption may be associated with a low risk of abnormal HDLcholesterol. Prospective studies with large sample sizes would be required to further investigate this association.

Keywords: abdominal obesity, blood lipid, HDL-C

\section{Introduction}

Obesity is a global health problem. From 1980 to 2013, the global prevalence of adult overweight and obesity increased by $27.5 \%$ and $47.1 \%$, respectively. The number of people with overweight and obesity increased from 857 million in 1980 to 2.1 billion in 2013. ${ }^{1}$ Obesity is an important risk factor for various chronic diseases, such as hyperlipidemia, hypertension, type 2 diabetes, fatty liver disease, heart disease, and cancer. ${ }^{2}$ Obesity-related costs are huge and have become a huge financial burden. ${ }^{3}$ Therefore, the high burden of obesity-related diseases has prompted people to find new and improved strategies to prevent and alleviate obesity. 
As a daily beverage, green tea has shown beneficial health effects, especially its weight loss effect. Green tea can reduce the micellar solubility of cholesterol at the intestinal level, thereby reducing its absorption. ${ }^{4}$ It can also reduce low-density lipoprotein levels, increase the total antioxidant capacity of plasma, ${ }^{5}$ increase energy consumption, ${ }^{6}$ promote thermogenesis and fat oxidation, ${ }^{7}$ and relieve hyperlipidemia. ${ }^{8}$ Tea is highly valued because of its taste, aroma, health benefits, and various social and cultural reasons. ${ }^{4}$

Oil tea is a daily drink in northeastern Guangxi, China. The Gongcheng oil tea is a typical representative of oil tea and has now become a geopolitically distinctive food product. The Gongcheng oil tea preparation process is as follows: put tea, ginger, edible oil into a dedicated iron teapot and stir-fried. Subsequently, these raw materials are uniformly mashed with a like "7" shape wooden mallet and simmered with boiling water for $10 \mathrm{~min}$. The mixture is filtered, and the residuum is repeated mash, boil thrice. Tea contains tea polyphenols, soluble polysaccharides, and caffeine, and ginger contains gingerol. These substances have various pharmacological effects, such as anti-allergic, antioxidant, anti-inflammatory, neuroprotective, and antiobesity. ${ }^{9,10}$ Traditional Chinese medicine believes that drinking oil tea is good for health. At present, some animal experiments have found that oil tea reduces body weight and improves blood lipid levels in hyperlipidemic rats and diabetic mice. ${ }^{11,12}$ However, the effect of oil tea on human health has not been confirmed yet. Therefore, we conducted an epidemiological survey to investigate the relations of oil tea consumption with obesity and dyslipidemia. In local eating habits, residents are used to cooking oil tea at mealtimes, people who drink more oil tea would take longer to eat and eat more food. In addition, oil tea is commonly used as the base of hot pot in local areas, resulting in increased oil tea consumption, which is often accompanied by an increase in the intake of meat food and local specialty fried snacks. It is not clear whether excessive consumption of meat and other foods will affect the lipid-lowering function of oil tea. Therefore, we need to control the influence of dietary factors.

\section{Materials and Methods}

\section{Participants}

The site of this study was Gongcheng Yao Autonomous County, Guangxi, China.
According to the cross-sectional sampling survey sample size calculation formula:

$$
\mathrm{N}=\left(\mathrm{Z}_{\alpha}^{2} \times \mathrm{pq}\right) / \mathrm{d}^{2}
$$

$\mathrm{N}$ is the sample size, $\mathrm{Z}$ is the statistical quantity, $\alpha=0.05$, $\mathrm{Z}=1.96, \mathrm{p}$ is the expected prevalence, $\mathrm{q}=1-\mathrm{p}, \mathrm{d}$ is the allowable error, $\mathrm{d}=0.1 \mathrm{p}$. The expected prevalence of obesity in middle-aged and elderly people was about $18 \%,{ }^{13}$ the expected prevalence of central obesity was $44 \%,{ }^{14}$ and the expected prevalence of dyslipidemia was $44.2 \%{ }^{15}$ The estimated sample size for this study was 1749 , to which $10 \%-15 \%$ of the sample was added. Study subjects were selected who met the following criteria: a) resided in the study area; b) were 30 years of age and older; c) complete blood test, height, weight, waist circumference, and questionnaire information; d) plausible energy intake, between $600-4000 \mathrm{kcal}$. Finally, a total of 2001 adults aged 30 years and over were included in this study (2018-2019). The present study was conducted according to the guidelines laid down in the Declaration of Helsinki, and all procedures involving human subjects were approved by the Ethics Committee of Guilin Medical University. Written informed consent was obtained from all the subjects.

\section{Anthropometry}

Participants were asked to remove their shoes, hats, and coats and to wear only close-fitting clothing for height, weight, and waist measurements. The instrument was calibrated before the test, the weight was measured to an accuracy of $0.1 \mathrm{~kg}$ using a weight scale, and the height was measured to an accuracy of $0.1 \mathrm{~cm}$ using a metal column type height meter. The waist circumference was measured to an accuracy of $0.1 \mathrm{~cm}$ using a leather ruler $1 \mathrm{~cm}$ above the navel. Blood pressure was measured using an electronic sphygmomanometer (HEM -7112; Omron) calibrated with a mercury column sphygmomanometer, and the subjects were placed in a sitting or supine position with their arms flat and at the same height as their hearts. All study subjects collected fasting blood samples from cubital veins in the morning after fasting for at least 12 hours. Fasting blood glucose (FPG) was tested by a blood routine analyzer (Sysmex CS-1600, Shanghai, China). Serum total cholesterol (TC), triglycerides (TG), lowdensity lipoprotein cholesterol (LDL-C), and high-density lipoprotein cholesterol (HDL-C) were tested by a blood biochemical detector (Hitachi 7600-020, Kyoto, Japan) at Gongcheng County People's Hospital. 


\section{Assessment of Food Intake and Oil Tea Consumption}

Diet was assessed by a food frequency questionnaire (FFQ) referring to the questionnaire designed by Liu et $\mathrm{al}^{16}$ and Wang et al. ${ }^{17}$ The contents of energy and nutrients in food were referred to Chinese Food Composition Table (2009). ${ }^{18}$ The research subjects were asked to select the bowl from a set of standard bowls of different specifications to describe the intake of oil tea and an electronic balance was used to weigh the raw materials in oil tea. The participants who consumed oil tea daily were divided into five groups based on their non-consumption status and quartile of consumption from low to high (groups nondrink oil tea, Q1-Q4). The Q1-Q4 groups had the following daily oil tea consumption: $5.36 \mathrm{~mL}<\mathrm{Q} 1 \leq 260 \mathrm{~mL}$, $260 \mathrm{~mL}<\mathrm{Q} 2 \leq 400 \mathrm{~mL}, 400 \mathrm{~mL}<\mathrm{Q} 3 \leq 720 \mathrm{~mL}$, and Q4 $>720 \mathrm{~mL}$. The same grouping method was used for the tea and ginger content in oil tea.

\section{Diagnostic Criteria for Dyslipidemia}

According to the National Cholesterol Education Panel (NCEP) Adult Treatment Panel III (ATP III) to classify dyslipidemia. ${ }^{19}$ The high TC was TC $\geq 6.22 \mathrm{mmol} / \mathrm{L}$, the high TG was $\mathrm{TG} \geq 2.26 \mathrm{mmol} / \mathrm{L}$, the high $\mathrm{LDL}-\mathrm{C}$ was LDL-C $\geq 4.14 \mathrm{mmol} / \mathrm{L}$, the low-HDL-C was HDL-C < $1.04 \mathrm{mmol} / \mathrm{L}$. According to the WHO-recommended diagnostic criteria of obesity for Asian populations, ${ }^{20}$ overweight and obesity were indicated by $23.0 \mathrm{~kg} / \mathrm{m}^{2} \leq$ BMI $<27.5 \mathrm{~kg} / \mathrm{m}^{2}$ and BMI $\geq 27.5 \mathrm{~kg} / \mathrm{m}^{2}$, respectively; abdominal obesity was defined as $\mathrm{WC} \geq 90 \mathrm{~cm}$ in men and $\mathrm{WC} \geq$ $80 \mathrm{~cm}$ in women.

\section{Assessment of Covariates}

Information on age, ethnicity, education level, tobacco smoking, and alcohol consumption were obtained in the face-to-face interviews using standardized and structured questionnaires. Smoking was defined as currently smoking at least one cigarette per day. Alcohol consumption was defined as drinking at least $50 \mathrm{~g}$ of alcohol or more at least once a month. The participants who were retired or doing housework, unemployed for more than one year, or physically disabled were considered to be not working. Occupations that involved mainly sitting or standing at work, such as administrative staff, salespersons, and doormen, were defined as light physical activities. Occupations that focused on general physical activity at work, such as woodwork, electric maintenance, and construction, were defined as general physical activity. Occupations with heavy physical labor at work, such as porters, miners, loaders, and unloaders, were defined as heavy physical activities. The daily walking time was divided into $\leq 2$, $2-4$, and $>4 \mathrm{~h}$ according to the third quartile.

\section{Statistical Analysis}

Normally distributed data were described as mean \pm standard deviation, and comparison between groups was conducted via a $t$-test. Non-normally distributed data were defined with median plus interquartile range, and comparison between groups was performed via Wilcoxon or Kruskal-Wallis rank sum test. Categorical variables were described as observed numbers and percentages and compared via a chi-square test. The relationship between oil tea consumption and abnormal blood lipids was evaluated through logistics regression analysis. All statistical analyses were performed in SPSS software.

\section{Results}

\section{Demographic Characteristics of the Study Subjects}

A total of 2, 001 subjects with an average age of $57.20 \pm$ 11.60 years are enrolled in this study. The median volume consumption of oil tea in the population was $360 \mathrm{~mL}$. The medians of TC, TG, LDL-C, and HDL-C were 5.46, 1.05, 3.34 , and $1.70 \mathrm{mmol} / \mathrm{L}$, respectively. The prevalence rates of obesity, abdominal obesity, high TC, high TG, high LDL-C, and low HDL-C were 7.6\%, 30.5\%, 24.3\%, $13.0 \%, 21.6 \%$, and $0.7 \%$, respectively. (Table 1 ).

\section{Relationship Between Oil Tea Intake and Energy and Nutrient Intake}

In overall participants, the intakes of energy and protein in group Q2 were significantly higher than those in group Q1. The intakes of energy, protein, fat, carbohydrate and cholesterol in group Q3 were significantly higher than those in group Q1. The intakes of energy, protein, carbohydrate and cholesterol in group Q4 were significantly higher than those in the non-drinking oil tea group. The intakes of energy, fat, protein, carbohydrate and cholesterol in group Q4 were significantly higher than those in groups Q1 and groups Q2. In men, the intakes of energy, protein, fat, and cholesterol in group Q3 and Q4 were significantly higher than those in group Q1. The intakes of energy, carbohydrate and protein in group Q2 were significantly higher than those in group Q1 and the intakes of carbohydrate in 
Table I Baseline Characteristics of the Study Participants

\begin{tabular}{|c|c|c|c|c|}
\hline Characteristics & Overall $(n=2001)$ & Male $(n=750)$ & Female $(n=|25|)$ & $P$-value \\
\hline Age (years) & $57.20 \pm 11.60$ & $58.90 \pm \mid 1.51$ & $56.18 \pm 11.55$ & $<0.001$ \\
\hline Ethnicity n (\%) & & & & 0.167 \\
\hline Han & $373(18.6)$ & $131(17.5)$ & $242(19.3)$ & \\
\hline Yao & $1524(76.2)$ & $587(78.3)$ & 937 (74.9) & \\
\hline Others & $104(5.2)$ & $32(4.3)$ & $72(5.8)$ & \\
\hline Education time $\mathrm{n}(\%)$ & & & & $<0.001$ \\
\hline$\leq 6$ year & $1328(66.4)$ & $394(52.5)$ & $934(74.7)$ & \\
\hline$>6$ year & $673(33.6)$ & $356(47.5)$ & $317(25.3)$ & \\
\hline Smoking & $355(17.7)$ & $350(46.7)$ & $5(0.4)$ & $<0.001$ \\
\hline Drinking & 679 (33.9) & $424(56.5)$ & $255(20.4)$ & $<0.001$ \\
\hline Daily consumption of oil tea $(\mathrm{mL})$ & $360.00(240.00-720.00)$ & $480.00(300.00-720.00)$ & $360.00(220.00-640.00)$ & $<0.001$ \\
\hline Tea content in oil tea $(\mathrm{g})$ & $8.12(4.08-15.33)$ & $9.55(4.70-17.12)$ & $7.46(3.61-14.23)$ & $<0.001$ \\
\hline Ginger content in oil tea $(\mathrm{g})$ & $9.33(4.88-16.76)$ & $10.00(5.06-17.93)$ & $8.90(4.76-16.08)$ & 0.02 \\
\hline Daily energy intake (kcal) & $1515.94(1144.49-2018.46)$ & I 647.37 (I24I.4-2194.5) & | 408.52 (1085.99-1904.59) & $<0.001$ \\
\hline Daily protein intake (g) & $36.74(25.18-54.7 I)$ & $4 I . I I(28.2-60.28)$ & $34.52(23.6-50.72)$ & $<0.001$ \\
\hline Daily fat intake (g) & $65.83(45.01-94.95)$ & $74.26(50.77-103.02)$ & $62.14(42.59-90.4 I)$ & $<0.001$ \\
\hline Daily carbohydrate intake (g) & |87.7| (|38.94-25|.20) & 201.31 (144.60-273.44) & $180.46(\mid 33.27-237.1 \mathrm{I})$ & $<0.001$ \\
\hline Daily cholesterol intake (mg) & $210.52(101.92-361.15)$ & $213.49(106.45-366.83)$ & $209.98(98.63-359.99)$ & 0.423 \\
\hline Physical activity level at work $\mathrm{n}(\%)$ & & & & 0.001 \\
\hline Not working & $689(34.4)$ & $232(30.9)$ & $457(36.5)$ & \\
\hline Light physical activity & $97(4.8)$ & $37(4.9)$ & $60(4.8)$ & \\
\hline General physical activity & || $7 \mid(58.5)$ & $454(60.5)$ & $717(57.3)$ & \\
\hline Heavy physical activity & $44(2.2)$ & $27(3.6)$ & $17(1.4)$ & \\
\hline Walking time $\mathrm{n}(\%)$ & & & & 0.095 \\
\hline$\leq 2 \mathrm{~h} /$ day & 798 (39.9) & $316(42.1)$ & $482(38.5)$ & \\
\hline $2-4 \mathrm{~h} /$ day & $583(29.1)$ & $198(26.4)$ & $385(30.8)$ & \\
\hline$>4 \mathrm{~h} /$ day & $620(31.0)$ & $236(3 \mid .5)$ & $384(30.7)$ & \\
\hline Systolic pressure $(\mathrm{mmHg})$ & 131 (118-149) & $129(115-146)$ & $133(|2|-|5|)$ & $<0.001$ \\
\hline Diastolic pressure $(\mathrm{mmHg})$ & 81 (73-90) & $79(73-88)$ & $82(74-9 \mid)$ & 0.001 \\
\hline FPG (mmol/L) & $4.71(4.36-5.16)$ & $4.77(4.37-5.21)$ & $4.68(4.36-5.12)$ & 0.014 \\
\hline Obesity & $|5|(7.6)$ & $58(7.7)$ & $93(7.4)$ & 0.806 \\
\hline Abdominal obesity & $610(30.5)$ & $126(16.8)$ & $484(38.7)$ & $<0.001$ \\
\hline $\mathrm{TC}(\mathrm{mmol} / \mathrm{L})$ & $5.46(4.82-6.20)$ & $5.44(4.80-6.20)$ & $5.47(4.85-6.19)$ & 0.334 \\
\hline $\mathrm{TG}(\mathrm{mmol} / \mathrm{L})$ & $1.05(0.74-1.63)$ & $1.04(0.72-1.60)$ & $1.06(0.75-1.63)$ & 0.645 \\
\hline LDL-C (mmol/L) & $3.34(2.73-4.01)$ & $3.38(2.77-4.02)$ & $3.33(2.70-4.00)$ & 0.363 \\
\hline $\mathrm{HDL}-\mathrm{C}(\mathrm{mmol} / \mathrm{L})$ & $1.70(1.46-1.99)$ & $1.63(1.41-1.93)$ & $1.74(1.49-2.03)$ & $<0.001$ \\
\hline Taking lipid-lowering drugs n (\%) & $17(0.8)$ & $8(1.1)$ & $9(0.7)$ & 0.413 \\
\hline High TC n (\%) & $487(24.3)$ & $185(24.7)$ & $302(24.1)$ & 0.791 \\
\hline High TG n (\%) & $260(13.0)$ & $108(14.4)$ & $152(12.2)$ & 0.147 \\
\hline High LDL-C n (\%) & $432(21.6)$ & $163(21.7)$ & $269(21.5)$ & 0.903 \\
\hline Low HDL-C n (\%) & $15(0.7)$ & $7(0.9)$ & $8(0.6)$ & 0.461 \\
\hline
\end{tabular}

Abbreviations: FPG, fasting blood glucose; TC, total cholesterol; TG, triglycerides; LDL-C, low-density lipoprotein cholesterol; HDL-C, high-density lipoprotein cholesterol.

Q4 was significantly higher than those in the non-drinking oil tea group. In women, the intakes of energy, protein, and carbohydrate in group Q4 were significantly higher than those in group Q1. The intakes of energy and cholesterol in group Q4 were significantly higher than those in group Q3 (Figure 1). 
A

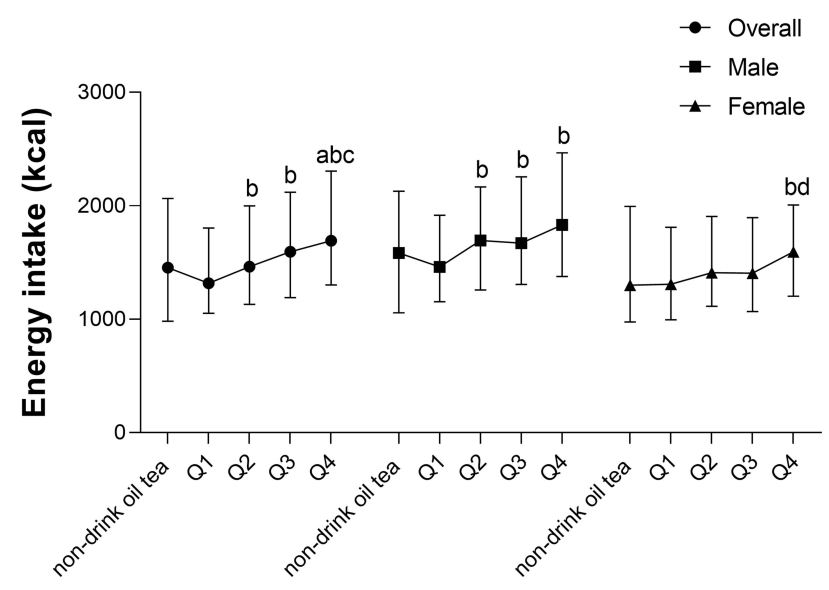

C
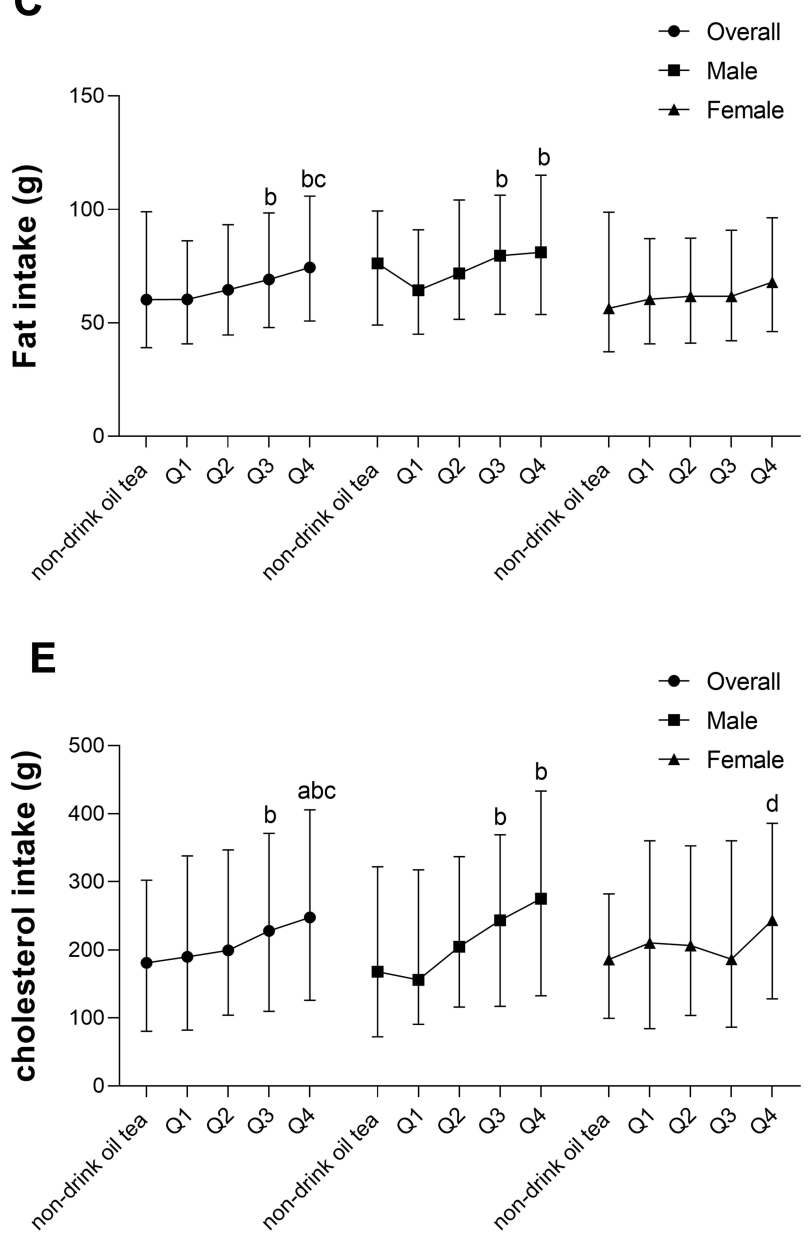

B
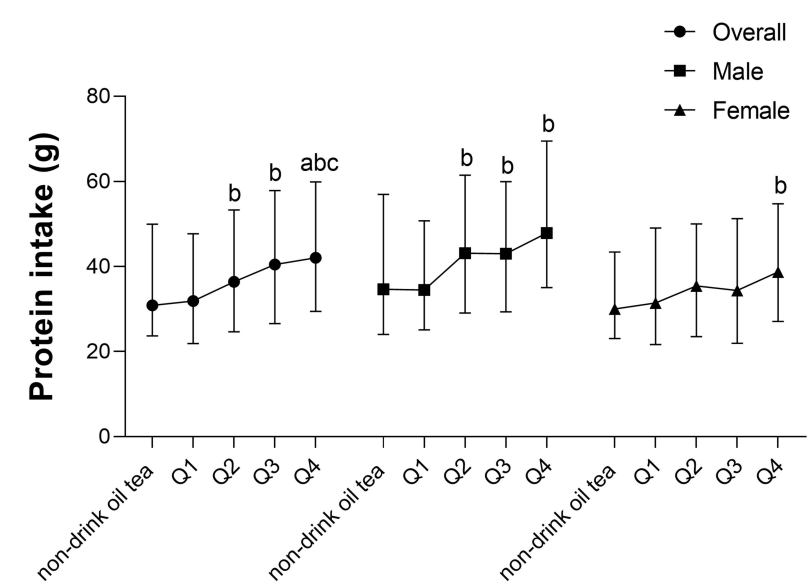

D

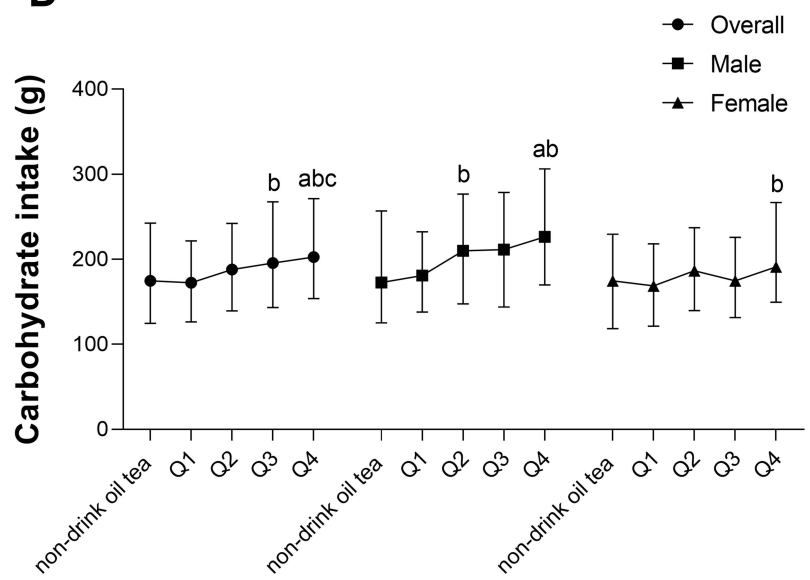

Figure I Relationship between oil tea intake and energy and nutrient intake. (A) Energy intake, (B) Protein intake, (C) Fat intake, (D) Carbohydrate intake, (E) Cholesterol

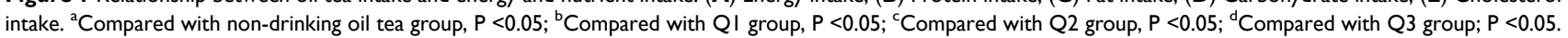

Association of Daily Consumption of Oil Tea with Obesity and Dyslipidemia

In overall participants, the TC and LDL-C levels in the Q2 group were significantly higher than those in the non-drink oil tea group. The TG level in the Q3 group was significantly lower than that in the non-drink oil tea group and the Q1 group. The HDL-C levels in the Q2 and Q3 groups were significantly higher than those in the non-drink oil tea group. 
In men, the systolic pressure in the Q4 group was significantly lower than that in the Q1 group, and the diastolic pressure in the Q2, Q3, and Q4 group was significantly lower than that in the Q1 group. In women, the HDL-C level in the Q4 group was significantly higher than that in the non-drink oil tea group and Q1 group (Figure 2).

The incidence of abdominal obesity and low HDL-C tended to decrease significantly ( $\mathrm{P}$ for trend $<0.05$ ) with
A

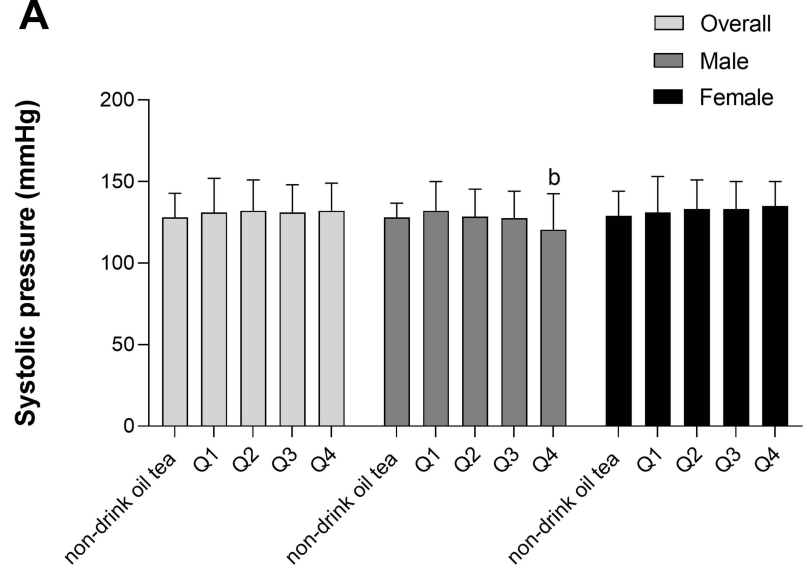

C

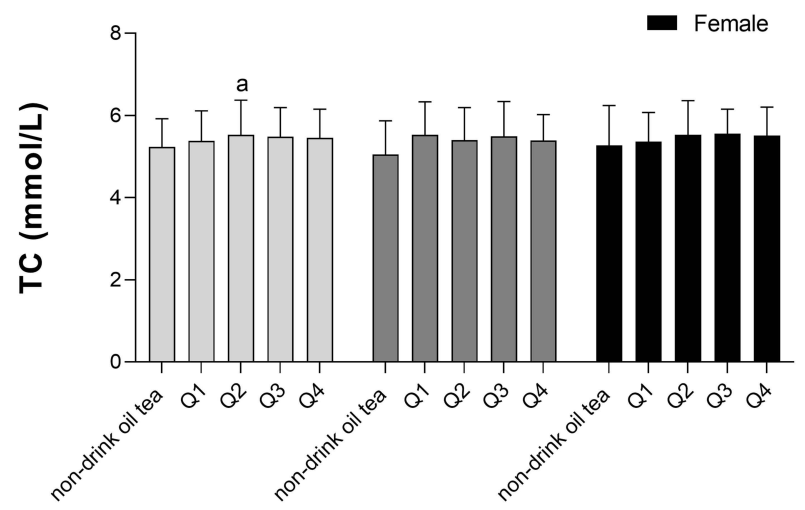

E

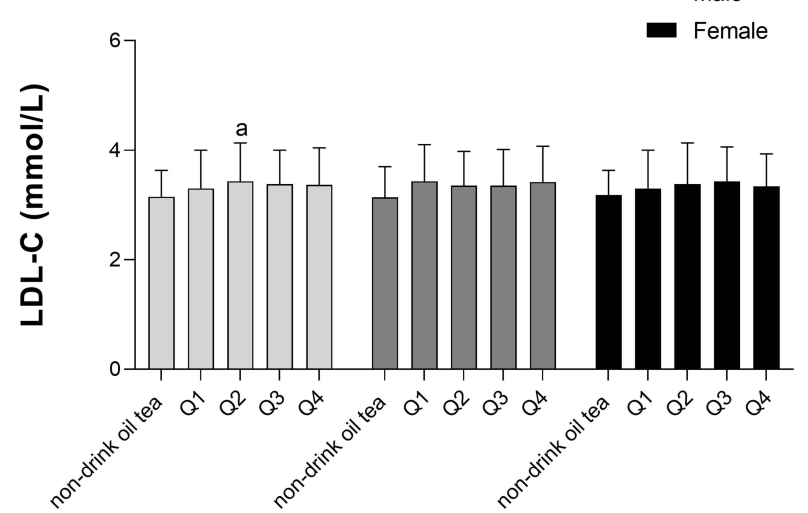

B

$\square$ Overall

$\square$ Male
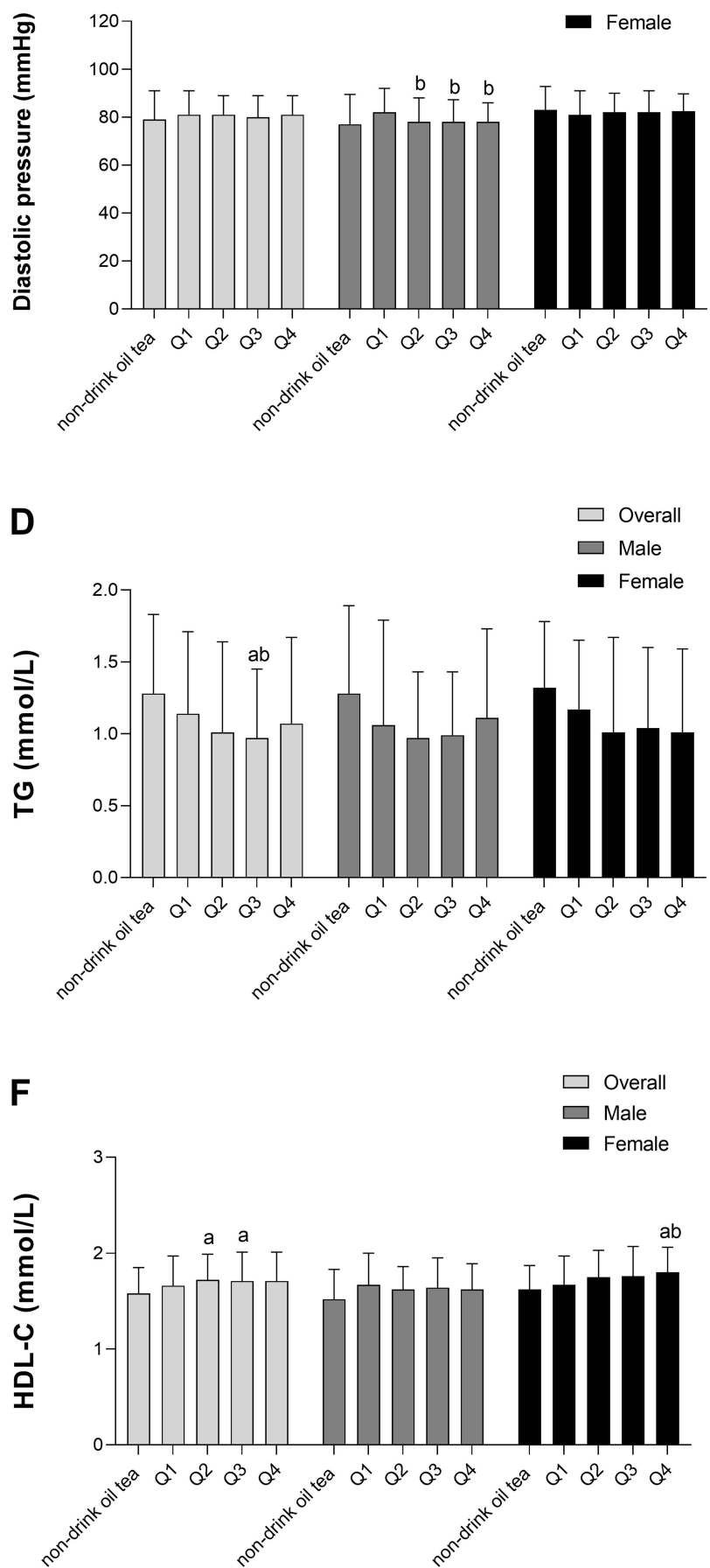

Figure 2 Effect of oil tea on blood lipid indicators. (A) Systolic pressure; (B) Diastolic pressure; (C) TC: total cholesterol; (D) TG: triglycerides; (E) LDL-C: low-density lipoprotein cholesterol (F) HDL-C: high-density lipoprotein cholesterol. a Compared with non-drinking oil tea group, $P<0.05$; ${ }^{\mathrm{b}} \mathrm{Compared}$ with $\mathrm{Q}$ I group, $P<0.05$. 
increasing daily consumption of oil tea (Table 2). In the multiple regression model, oil tea consumption significantly reduced the risk of abdominal obesity and low HDL-C ( $\mathrm{P}$ for trend $<0.05$ ) in overall participants. The Q3 and Q4 groups were related to a low risk of abdominal obesity, the OR values were 0.545 (95\% CI:0.336$0.884)$ and 0.520 (95\% CI:0.311-0.871). The daily consumption of oil tea groups Q1, Q2, Q3, and Q4 were associated with a low risk of low HDL-C, the OR values were 0.191 (95\% CI: $0.037-0.982), 0.177$ (95\% CI: $0.032-0.973), 0.085$ (95\% CI: 0.014-0.517) and 0.045 (95\% CI: 0.004-0.538), respectively. When the stratified analysis was performed according to gender. The results were significant only for women and there was a decreasing trend of abdominal obesity with increasing oil tea consumption. In women, the Q2 group was associated with a high risk of high LDL-C, the OR value was 2.600 (95\% CI: 1.033-6.546) (Table 3).

\section{Association of Tea Content in Oil Tea with Obesity and Dyslipidemia}

In overall participants, the Q4 group was related to a low risk of abdominal obesity when compared with the nondrink oil tea group, the OR value was 0.537 (95\% CI: $0.327-0.881)$. The tea content in oil tea significantly reduced the risk of low HDL-C ( $\mathrm{P}$ for trend $<0.05$ ). The Q1, Q2, Q3, and Q4 groups were associated with a lower risk of low HDL-C when compared with the non-drink oil tea group, the OR values were 0.176 (95\% CI: 0.034 0.924), 0.171 (95\% CI: 0.032-0.915), 0.074 (95\% CI: $0.010-0.549)$ and 0.073 (95\% CI: 0.010-0.537), respectively. When the stratified analysis was performed according to gender. The association of tea content in oil tea with abdominal obesity and low HDL-C were significant only for women and there was a decreasing trend of abdominal obesity with increasing tea content in oil tea. In men, the tea content in oil tea significantly increased the risk of high TC ( $\mathrm{P}$ for trend $<0.05$ ). However, no significant difference was found in the association between tea content in oil tea and high TC. In women, the Q2 group was associated with a high risk of high LDL-C, the OR value was $2.760(95 \%$ CI: 1.096-6.950) (Table 4).

\section{Association of Ginger Content in Oil Tea with Obesity and Dyslipidemia}

In overall participants, the Q1 and Q2 group were associated with a low risk of abdominal obesity, the OR values were 0.612 (95\% CI: $0.375-0.998)$ and 0.579 (95\% CI: 0.354-0.945), respectively. The Q1 and Q4 groups were associated with a low risk of low HDL-C, the OR values were 0.047 (95\% CI: 0.004-0.527) and 0.113 (95\% CI: $0.018-0.700)$, respectively. When the stratified analysis was performed according to gender. The results were significant only for women (Table 5).

\section{Discussion}

Most Asian individuals with obesity are categorized to have abdominal obesity. They often deposit excessive visceral fat, and this insulin resistance is usually serious, difficult to correct, and closely related to cardiovascular disease. ${ }^{21}$ The prevalence rate of abdominal obesity in the study population was $30.5 \%$, which was $12 \%$ lower than the prevalence rate in the China Health and Nutrition Survey. $^{22}$

In this study, we found that as the consumption of oil tea increases, the intake of carbohydrates, fats, and cholesterol increases. Higher carbohydrate consumption was associated with higher hypertriglyceridemia and low HDL levels. $^{23}$ In addition, higher intakes of total fat and cholesterol were associated with higher TC and LDL-C

Table 2 Distribution of Obesity and Dyslipidemia Among Different Oil Tea Groups

\begin{tabular}{|c|c|c|c|c|c|c|}
\hline \multirow[t]{2}{*}{ Characteristics } & \multirow[t]{2}{*}{ Non-Drinking Oil Tea $(n=92)$} & \multicolumn{4}{|c|}{ Daily Consumption of Oil Tea } & \multirow[t]{2}{*}{ P for Trend } \\
\hline & & QI $(n=48 I)$ & Q2 (n=48I) & Q3 (n=614) & Q4 (n=333) & \\
\hline Obesity n (\%) & $8(8.7)$ & $39(8.1)$ & $35(7.3)$ & $43(7.0)$ & $26(7.8)$ & 0.635 \\
\hline Abdominal obesity $\mathrm{n}(\%)$ & $37(40.2)$ & I7I (35.6) & $156(32.4)$ & $165(26.9)$ & $81(24.3)$ & $<0.001$ \\
\hline High TC n (\%) & $19(20.7)$ & $112(23.3)$ & $132(27.4)$ & $145(23.6)$ & $79(23.7)$ & 0.879 \\
\hline High TG n (\%) & II (12.0) & $78(16.2)$ & $63(13.1)$ & $67(10.9)$ & $4 I(12.3)$ & 0.072 \\
\hline High LDL-C n (\%) & $14(15.2)$ & $100(20.8)$ & $117(24.3)$ & $127(20.7)$ & $74(22.2)$ & 0.498 \\
\hline Low HDL-C n (\%) & $3(3.3)$ & $4(0.8)$ & $4(0.8)$ & $3(0.5)$ & $\mathrm{I}(0.3)$ & 0.029 \\
\hline
\end{tabular}

Abbreviations: TC, total cholesterol; TG, triglycerides; LDL-C, low-density lipoprotein cholesterol; HDL-C, high-density lipoprotein cholesterol. 


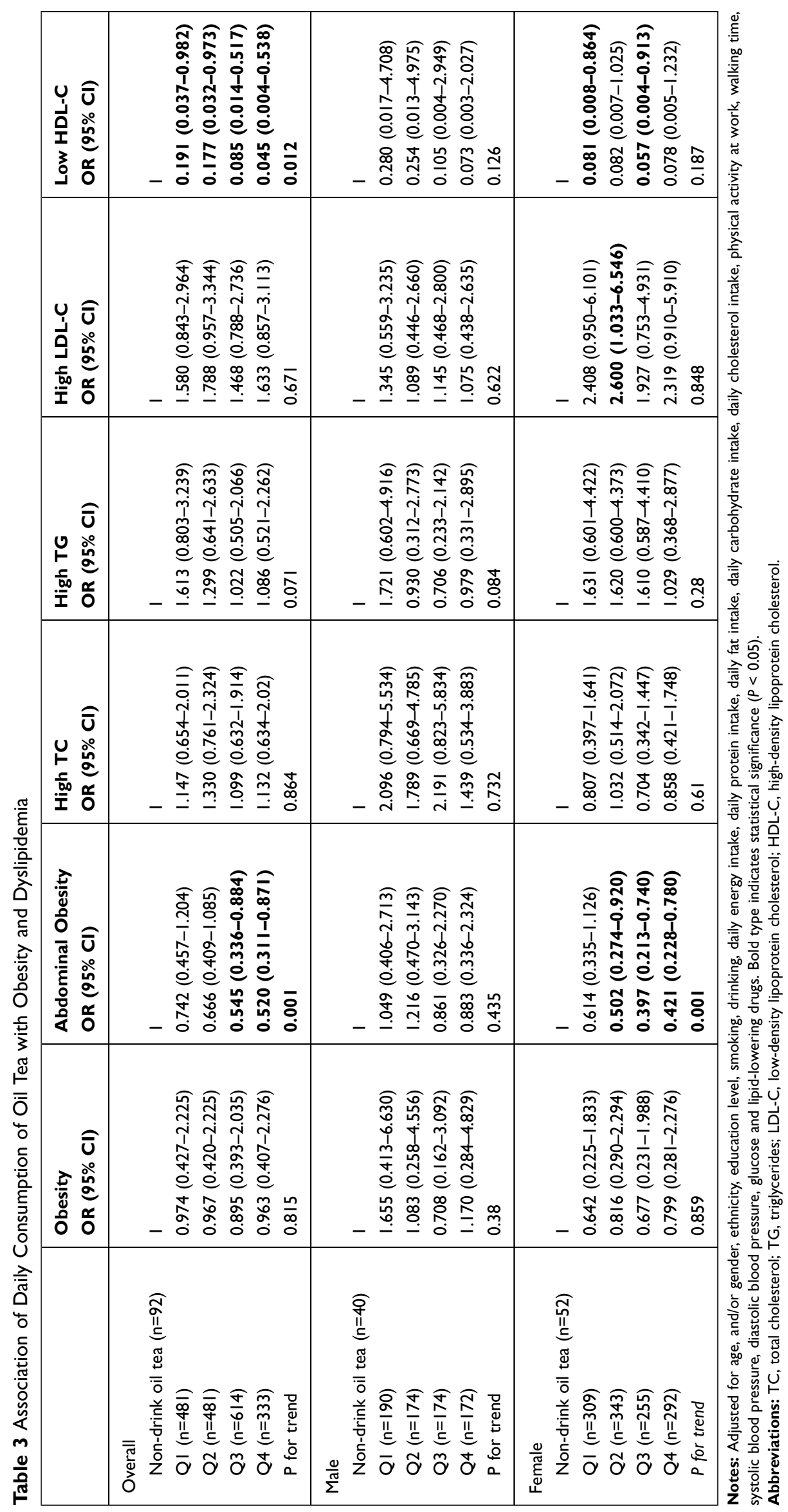




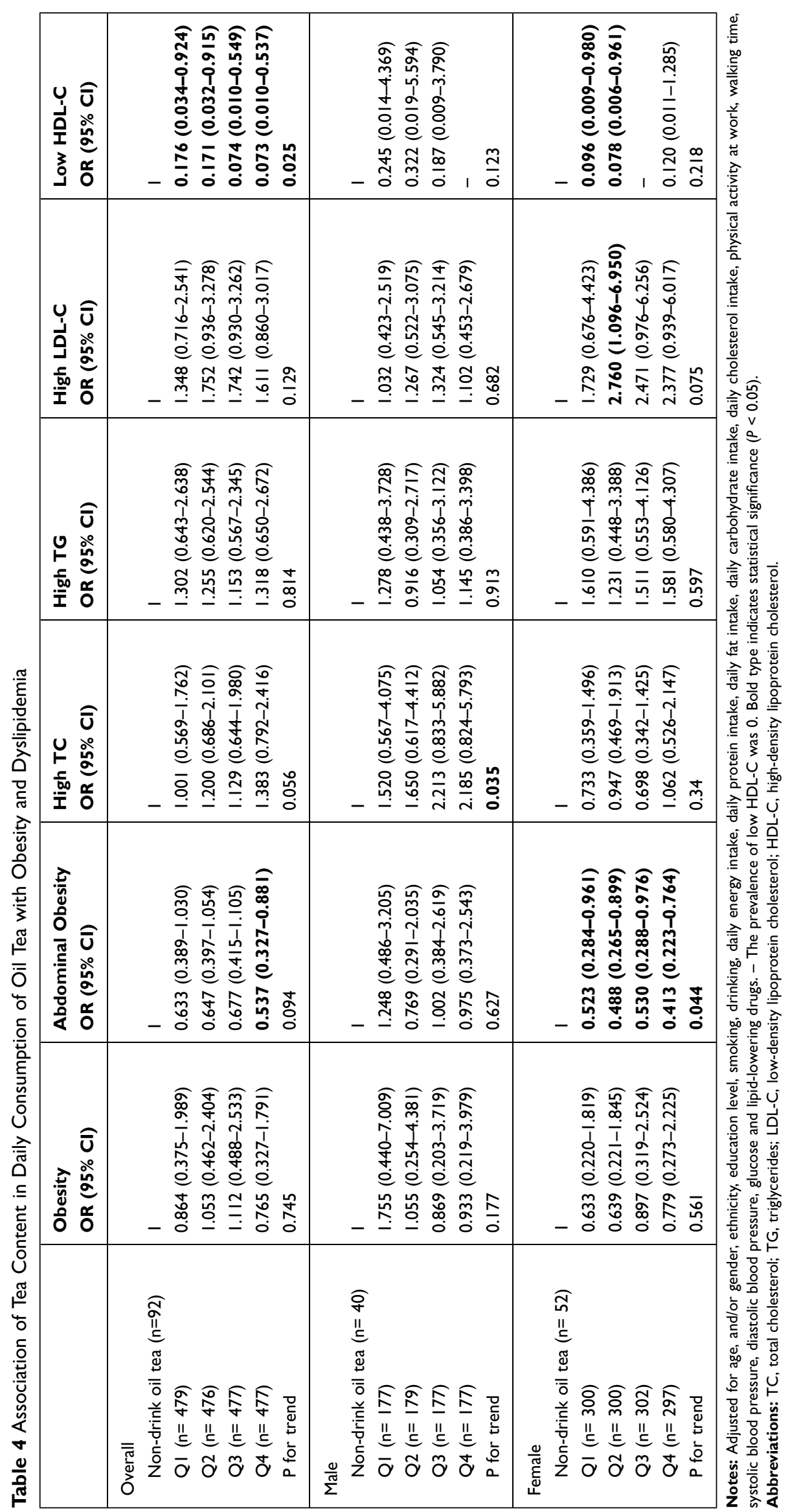




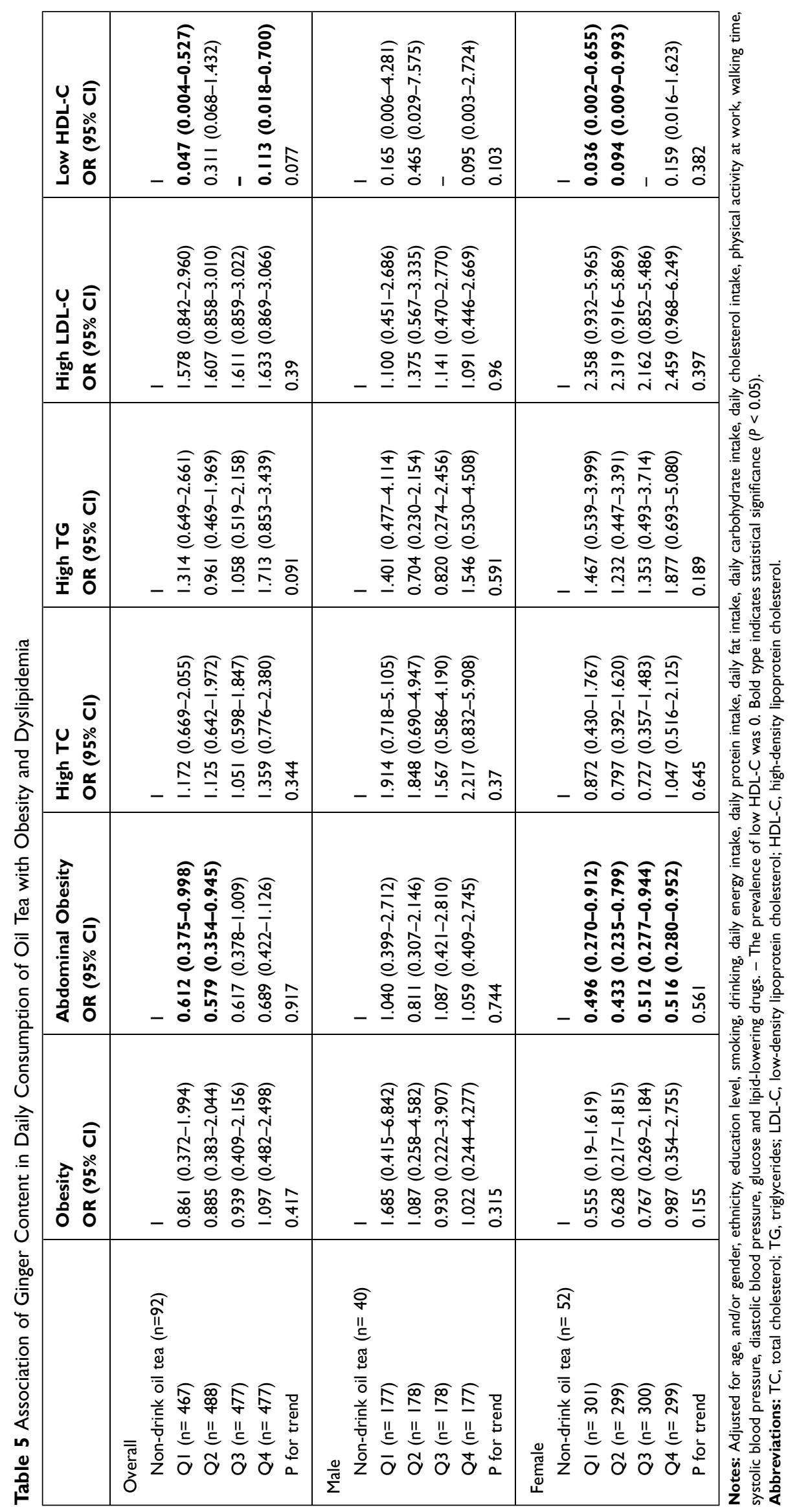


levels. $^{24}$ Oil tea consumption was accompanied by an increase in energy and carbohydrate, fat and cholesterol intake, which may explain the higher TC and LDL-C levels in the Q2 group compared to the non-oil tea consuming group. For this reason, dietary energy and nutrient intakes have been adjusted.

Previous epidemiological investigations found that drinking tea has the effect of losing weight. Bouchard et $\mathrm{al}^{25}$ found that men who drank more than 2 cups of tea per day had lower BMI and WC values than men who never drank drink tea. However, after adjusting for additive use, the association between tea consumption and BMI or WC were no longer significant. Nagao et $\mathrm{al}^{26}$ found that the loss of weight, body fat mass, WC, and subcutaneous fat area of patients who have abdominal obesity and receive $583 \mathrm{mg}$ of catechin daily for 12 weeks are more than those of patients who have abdominal obesity and take $96 \mathrm{mg}$ of catechins daily. After adjustment for covariates, our study demonstrates oil tea consumption was significantly and negatively associated with the risk of abdominal obesity. When we stratified the analysis according to gender, only the results for women were significant. A cross-sectional study from Poland also found a significant reduction in the prevalence of abdominal obesity in women with increased tea intake, but no significant association in men. ${ }^{27}$ Some studies did not find a significant reduction in waist circumference with green tea consumption. ${ }^{28,29}$ In this study, oil tea plays a weightreducing effect likely because it has a variety of raw materials, such as tea leaf and ginger. Green tea extract was shown to have the ability to reduce body weight and fat accumulation. ${ }^{30}$ Ginger is thought to have a weightregulating effect alone. ${ }^{10,31}$

In overall participants, the prevalence of low HDL-C decreased significantly with increasing oil tea consumption and the tea content in oil tea. Previous epidemiological investigations have also found a beneficial effect of tea consumption on HDL-C. A National Health and Nutrition Examination survey in the US found that hot tea consumption was associated with beneficial biomarkers of cardiovascular disease risk, such as HDL-C. ${ }^{32}$ A population-based case-control study in China found that oolong tea consumption significantly reduced the risk of low HDL-C. ${ }^{33} \mathrm{We}$ found that the Q2 groups of oil tea consumption and the tea content in oil tea were associated with a high risk of High LDL-C in women. However, there was no significant increasing trend of high LDL-C with the increase of oil tea consumption. Our results suggest that consumption of high doses of oil tea was not associated with high LDL-C, while high doses of oil tea in the overall participants have a reduced risk of low HDL-C. Traditional Chinese medicine generally consists of different compounds acting in synergy to fully exploit their beneficial effects in the form of a total extract. Tea polyphenols may inhibit intestinal lipid absorption and increase the excretion of bile acids, cholesterol, and total lipids, ${ }^{34,35}$ these effects help to reduce the metabolic abnormalities and fatty liver disease caused by a high-fat diet. Besides, tea polyphenols can promote lipid metabolism by activating AMP-activated protein kinase, thereby attenuating lipogenesis, promoting lipolysis, and reducing lipid accumulation by inhibiting the differentiation and proliferation of preadipocytes. ${ }^{36,37}$ Gingerol may be related to promoting insulin sensitivity by regulating cell energy metabolism or reducing free fatty acid contents. Furthermore, gingerol may inhibit pancreatin activity by reducing fat and cholesterol absorption, thereby inhibiting the increase in plasma and tissue lipid levels. ${ }^{38} \mathrm{Zhu}$ et $\mathrm{al}^{11}$ found that oil tea was also rich in soluble sugar and caffeine. Tea polysaccharides can inhibit obesity by affecting fatty acid biosynthesis, steroid hormone biosynthesis, unsaturated fatty acid biosynthesis, fatty acid extension, and glycerophospholipid metabolism. ${ }^{39}$ Caffeine reduces weight by decreasing food intake, ${ }^{40}$ increasing energy expenditure at rest, $^{41}$ and improving athletic ability. ${ }^{42}$ Therefore, the lipidlowering effect of oil tea may be caused by the interaction of multiple active substances.

In this study, we have carefully controlled for obesity and dyslipidemia risk factors. We use grams of tea and ginger to measure tea consumption. This may be a better measure of tea and ginger consumption that at least partially reflects the intake of active ingredients. Besides, our combined use of FFQ provides a more accurate assessment of usual intake than either parameter alone. There are some limitations to our study. First, the analysis is cross-sectional. While the associations found are interesting, it is noteworthy that the demographic associations do not indicate causality in any way. Second, the intake of oil tea and food used for assessment in this study was self-reported and to some extent influenced by the recall and social desirability bias. Third, although we adjusted for some potential confounders, the possibility of residual confounders could not be avoided. For example, the potential effect of $A P O E$ gene polymorphisms on LDL levels.

\section{Conclusion}

Oil tea consumption is negatively associated with abdominal obesity and high-dose oil tea consumption 
significantly reduced the risk of abnormal HDLcholesterol. Prospective studies with large sample sizes would be required to further investigate this association.

\section{Acknowledgments}

The study was supported by the National Natural Science Foundation of China (grant No.81760577, 81560523 and 81960583), the Guangxi Science and Technology Development Project (grant No. AD17129003 and AD18050005), the Natural Science Foundation for Innovation Research Team of Guangxi (grant No. 2019GXNSFGA245002) and the Guangxi Scholarship Fund of Guangxi Education Department of China.

\section{Disclosure}

The authors report no conflicts of interest in this work.

\section{References}

1. Ng M, Fleming T, Robinson M, et al. Global, regional, and national prevalence of overweight and obesity in children and adults during 1980-2013: a systematic analysis for the Global Burden of Disease Study 2013. Lancet. 2014;384(9945):766-781. doi:10.1016/s01406736(14)60460-8

2. Sun Y, Wang Y, Song P, et al. Anti-obesity effects of instant fermented teas in vitro and in mice with high-fat-diet-induced obesity. Food Funct. 2019;10(6):3502-3513. doi:10.1039/c9fo00162j

3. Finkelstein E, Trogdon J, Cohen J, Dietz W. Annual medical spending attributable to obesity: payer-and service-specific estimates. Health Aff. 2009;28(5):w822-831. doi:10.1377/hlthaff.28.5.w822

4. Pastoriza S, Mesías M, Cabrera C, Rufian-Henares JA. Healthy properties of Green and White teas: an update. Food Funct. 2017;8 (8):2650-2662.

5. Erba D, Riso P, Bordoni A, et al. Effectiveness of moderate green tea consumption on antioxidative status and plasma lipid profile in humans. J Nutr Biochem. 2005;16(3):144-149. doi:10.1016/j. jnutbio.2004.11.006

6. Dulloo AG, Duret C, Rohrer D, et al. Efficacy of a green tea extract rich in catechin polyphenols and caffeine in increasing 24-h energy expenditure and fat oxidation in humans. Am J Clin Nutr. 1999;70 (6):1040-1045. doi:10.1093/ajcn/70.6.1040

7. Diepvens K, Westerterp KR, Westerterp-Plantenga MS. Obesity and thermogenesis related to the consumption of caffeine, ephedrine, capsaicin, and green tea. Am J Physiol Regul Integr Comp Physiol. 2007;292(1):R77-85. doi:10.1152/ajpregu.00832.2005

8. Huang LH, Liu CY, Wang LY, Huang CJ, Hsu CH. Effects of green tea extract on overweight and obese women with high levels of low density-lipoprotein-cholesterol (LDL-C): a randomised, double-blind, and cross-over placebo-controlled clinical trial. BMC Complement Altern Med. 2018;18(1):294. doi:10.1186/s12906-018-2355-x

9. Xu R, Ye H, Sun Y, Tu Y, Zeng X. Preparation, preliminary characterization, antioxidant, hepatoprotective and antitumor activities of polysaccharides from the flower of tea plant (Camellia sinensis). Food Chem Toxicol. 2012;50(7):2473-2480. doi:10.1016/j. fct.2011.10.047

10. Wang J, Li D, Wang P, Hu X, Chen F. Ginger prevents obesity through regulation of energy metabolism and activation of browning in high-fat diet-induced obese mice. $J$ Nutr Biochem. 2019;70:105-115. doi:10.1016/j.jnutbio.2019.05.001
11. Zhu Z, Lin Z, Jiang H, et al. Hypolipidemic effect of Youcha in hyperlipidemia rats induced by high-fat diet. Food Funct. 2017;8 (4):1680-1687. doi:10.1039/c7fo00089h

12. Lin R, He X, Chen H, et al. Oil tea improves glucose and lipid levels and alters gut microbiota in type 2 diabetic mice. Nutr Res. 2018;57:67-77. doi:10.1016/j.nutres.2018.05.004

13. Chooi YC, Ding C, Magkos F. The epidemiology of obesity. Metabolism. 2019;92:6-10. doi:10.1016/j.metabol.2018.09.005

14. Du P, Wang HJ, Zhang B, et al. Prevalence of abdominal obesity among Chinese adults in 2011. J Epidemiol. 2017;27(6):282-286. doi:10.1016/j.je.2017.03.001

15. Huang Y, Gao L, Xie X, Tan SC. Epidemiology of dyslipidemia in Chinese adults: meta-analysis of prevalence, awareness, treatment, and control. Popul Health Metr. 2014;12(1):28. doi:10.1186/s12963014-0028-7

16. Liu X, Lin S, Song Q, Lao X, Yu IT. Reproducibility and validity of a food frequency questionnaire for assessing dietary consumption via the dietary pattern method in a chinese rural population. PLoS One. 2015;10(7):e0134627. doi:10.1371/journal.pone.0134627

17. Wang CJ, Yang TF, Wang GS, Zhao YY, Yang LJ, Bi BN. Association between dietary patterns and depressive symptoms among middle-aged adults in China in 2016-2017. Psychiatry Res. 2018;260:123-129. doi:10.1016/j.psychres.2017.11.052

18. Yang YX. Ingredient List of Chinese Food. 6th ed. Beijing: Peking University Medical Press; 2009.

19. Expert Panel on Detection, Evaluation, and Treatment of High Blood Cholesterol in Adults. Executive Summary of The Third Report of The National Cholesterol Education Program (NCEP) Expert panel on detection, evaluation, and treatment of high blood cholesterol in adults (Adult Treatment Panel III). JAMA. 2001;285(19):2486-2497. doi:10.1001/jama.285.19.2486.

20. WHO Expert Consultation. Appropriate body-mass index for Asian populations and its implications for policy and intervention strategies. Lancet. 2004;363(9403):157-163. doi:10.1016/s0140-6736(03) 15268-3.

21. Huang J, Wang Y, Xie Z, et al. The anti-obesity effects of green tea in human intervention and basic molecular studies. Eur J Clin Nutr. 2014;68(10):1075-1087. doi:10.1038/ejen.2014.143

22. Chen Y, Peng Q, Yang Y, et al. The prevalence and increasing trends of overweight, general obesity, and abdominal obesity among Chinese adults: a repeated cross-sectional study. BMC Public Health. 2019;19(1):1293. doi:10.1186/s12889-019-7633-0

23. Nabuco HCG, Tomeleri CM, Sugihara Junior P, et al. Lower protein and higher carbohydrate intake are related with altering metabolic syndrome components in elderly women: a cross-sectional study. Exp Gerontol. 2018;103:132-137. doi:10.1016/j.exger.2018.01.013

24. Toeller M, Buyken AE, Heitkamp G, et al. Associations of fat and cholesterol intake with serum lipid levels and cardiovascular disease: the EURODIAB IDDM Complications Study. Exp Clin Endocrinol Diabetes. 1999;107(8):512-521. doi:10.1055/s-0029-1232560

25. Bouchard DR, Ross R, Janssen I. Coffee, tea and their additives: association with BMI and waist circumference. Obes Facts. 2010;3 (6):345-352. doi:10.1159/000322915

26. Nagao T, Hase T, Tokimitsu I. A green tea extract high in catechins reduces body fat and cardiovascular risks in humans. Obesity. 2007;15(6):1473-1483. doi:10.1038/oby.2007.176

27. Micek A, Grosso G, Polak M, et al. Association between tea and coffee consumption and prevalence of metabolic syndrome in Poland - results from the WOBASZ II study (2013-2014). Int J Food Sci Nutr. 2018;69(3):358-368. doi:10.1080/09637486.2017.1362690

28. Jurgens TM, Whelan AM, Killian L, et al. Green tea for weight loss and weight maintenance in overweight or obese adults. Cochrane Database Syst Rev. 2012;12:Cd008650. doi:10.1002/14651858. CD008650.pub2 
29. Baladia E, Basulto J, Manera M, Martínez R, Calbet D. [Effect of green tea or green tea extract consumption on body weight and body composition; systematic review and meta-analysis]. Nutr Hosp. 2014;29(3):479-490. doi:10.3305/nh.2014.29.3.7118. [Portugese]

30. Chen LH, Chien YW, Liang CT, Chan CH, Huang HY. Green tea extract induces genes related to browning of white adipose tissue and limits weight-gain in high energy diet-fed rat. Food Nutr Res. 2017;61(1):1347480. doi:10.1080/16546628.2017.1347480

31. Maharlouei N, Tabrizi R, Lankarani KB, et al. The effects of ginger intake on weight loss and metabolic profiles among overweight and obese subjects: a systematic review and meta-analysis of randomized controlled trials. Crit Rev Food Sci Nutr. 2019;59(11):1753-1766. doi:10.1080/10408398.2018.1427044

32. Vernarelli JA, Lambert JD. Tea consumption is inversely associated with weight status and other markers for metabolic syndrome in US adults. Eur J Nutr. 2013;52(3):1039-1048. doi:10.1007/s00394-0120410-9

33. Yi D, Tan X, Zhao Z, et al. Reduced risk of dyslipidaemia with oolong tea consumption: a population-based study in southern China. $B r \quad J \quad$ Nutr. 2014;111(8):1421-1429. doi:10.1017/ s0007114513003644

34. Uchiyama S, Taniguchi Y, Saka A, Yoshida A, Yajima H. Prevention of diet-induced obesity by dietary black tea polyphenols extract in vitro and in vivo. Nutrition. 2011;27(3):287-292. doi:10.1016/j. nut.2010.01.019

35. Huang J, Feng S, Liu A, et al. Green tea polyphenol EGCG alleviates metabolic abnormality and fatty liver by decreasing bile acid and lipid absorption in Mice. Mol Nutr Food Res. 2018;62(4):1700696. doi: $10.1002 / \mathrm{mnfr} .201700696$
36. Bae UJ, Park J, Park IW, et al. Epigallocatechin-3-Gallate-Rich Green Tea Extract Ameliorates Fatty Liver and Weight Gain in Mice Fed a High Fat Diet by Activating the Sirtuin 1 and AMP Activating Protein Kinase Pathway. Am J Chin Med. 2018;46 (3):617-632. doi:10.1142/s0192415x18500325

37. Rocha A, Bolin AP, Cardoso CA, Otton R. Green tea extract activates AMPK and ameliorates white adipose tissue metabolic dysfunction induced by obesity. Eur J Nutr. 2016;55(7):2231-2244. doi:10.1007/ s00394-015-1033-8

38. Saravanan G, Ponmurugan P, Deepa MA, Senthilkumar B. Antiobesity action of gingerol: effect on lipid profile, insulin, leptin, amylase and lipase in male obese rats induced by a high-fat diet. J Sci Food Agric. 2014;94(14):2972-2977. doi:10.1002/jsfa.6642

39. Wu T, Xu J, Chen Y, Liu R, Zhang M. Oolong tea polysaccharide and polyphenols prevent obesity development in Sprague-Dawley rats. Food Nutr Res. 2018;62. doi:10.29219/fnr.v62.1599.

40. Racotta IS, Leblanc J, Richard D. The effect of caffeine on food intake in rats: involvement of corticotropin-releasing factor and the sympatho-adrenal system. Pharmacol Biochem Behav. 1994;48 (4):887-892. doi:10.1016/0091-3057(94)90196-1

41. Hursel R, Viechtbauer W, Dulloo AG, et al. The effects of catechin rich teas and caffeine on energy expenditure and fat oxidation: a meta-analysis. Obes Rev. 2011;12(7):e573-581. doi:10.1111/j.1467789X.2011.00862.x

42. Glade MJ. Caffeine-Not just a stimulant. Nutrition. 2010;26 (10):932-938. doi:10.1016/j.nut.2010.08.004

Diabetes, Metabolic Syndrome and Obesity: Targets and Therapy

Dovepress

\section{Publish your work in this journal}

Diabetes, Metabolic Syndrome and Obesity: Targets and Therapy is an international, peer-reviewed open-access journal committed to the rapid publication of the latest laboratory and clinical findings in the fields of diabetes, metabolic syndrome and obesity research. Original research, review, case reports, hypothesis formation, expert opinion and commentaries are all considered for publication. The manuscript management system is completely online and includes a very quick and fair peer-review system, which is all easy to use. Visit http://www.dovepress.com/testimonials.php to read real quotes from published authors.

Submit your manuscript here: https://www.dovepress.com/diabetes-metabolic-syndrome-and-obesity-targets-and-therapy-journal 